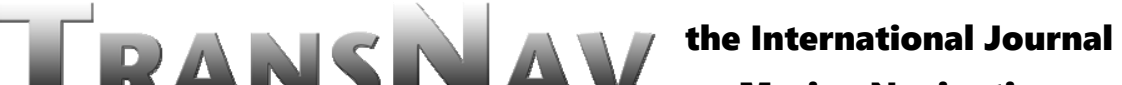

\section{Data Analysis to Evaluate Reliability of a Main Engine}

\author{
M. Anantharaman \& R. Islam \\ Australian Maritime College, University of Tasmania, Launceston, Australia \\ F. Khan \\ Memorial University of Newfoundland, St. John's, NL, Canada \\ V. Garaniya \& B. Lewarn \\ Australian Maritime College, University of Tasmania, Launceston, Australia
}

\begin{abstract}
Maritime transportation is the essence of international economy. Today, around ninety percent of world trade happens by maritime transportation via 50,000 merchant ships. These ships transport various types of cargo and manned by over a million mariners around the world. Majority of these ships are propelled by marine diesel engines, hereafter referred to as main engine, due to its reliability and fuel efficiency. Yet numerous accidents take place due to failure of main engine at sea, the main cause of this being inappropriate maintenance plan. To arrive at an optimal maintenance plan, it is necessary to assess the reliability of the main engine. At present the main engine on board vessels have a Planned Maintenance System (PMS), designed by the ship management companies, considering, advise of the engine manufacturers and/or ship's chief engineers and masters. Following PMS amounts to carrying out maintenance of a main engine components at specified running hours, without taking into consideration the assessment of the health of the component/s in question. Furthermore, shipping companies have a limited technical ability to record the data properly and use them effectively. In this study, relevant data collected from various sources are analysed to identify the most appropriate failure model representing specific component. The data collected, and model developed will be very useful to assess the reliability of the marine engines and to plan the maintenance activities on-board the ship. This could lead to a decrease in the failure of marine engine, ultimately contributing to the reduction of accidents in the shipping industry.
\end{abstract}

\section{INTRODUCTION}

Today modern merchant vessels have a huge cargo carrying capacity. Very large bulk carriers (VLBC) carry iron ore to a full capacity of 400,000 DWT (dead weight tonnes), (Proposes). Ultra large crude oil carriers (ULCC), have an oil carrving capacitv of 5000,00 DWT, (Ingle et al., 2010). The world's largest container vessel has a capacitv of 20,568 twentv-foot equivalent units (TEUs), (Kim et al., 2002). Moreover, liquid natural gas (LNG) have a tonnage carrying capacity of 128,900 DWT, with a cubic capacity of 266,000 cubic meters, (Pitblado et al., 2006). These huge vessels are propelled by large capacity marine diesel engines referred as a main engine. The main engine can produce power to the tune of $100 \mathrm{MW}$ (megawatts). To safely transport cargo from one port to another, it is important to ensure that the main engine propelling the giant vessels is safe and reliable. Moreover, it is an ongoing challenge for commercial shipping operators to deal with issues related to the protection of environment and legal implications on a day to day basis (Hatzigrigoris et al., 2005). Numerous marine accidents occurred due to the failure of main engines. In August 2001, a Hong Kong flagged, cellular container ship of 44153 deadweight tonnes "Maersk Tacoma" had an accident at sea due to the failure of lubricating oil system of a main 
engine (ATSB, 2001). In July 2006 the Antigua and Barbuda registered self-discharging bulk carrier Enterprise had an accident due to the failure of lubricating oil system of a main engine while en-route from Adelaide to Sydney, Australia. As a results of this failure main engine stopped and caused blackout of the ship at sea. Therefore, the ship had to be towed to the nearest port for repairs. The Australian Transport Safety Bureau (ATSB) investigation identified that maintenance planning for the main lubricating oil pump was inadequate and engineers did not follow the manufacturer's instructions, even though the pump had failed previously. Also, the execution of routine maintenance on the lubricating oil filter was inadequate in that the spare filter was not ready for use. The shipboard procedures did not identify the error and the procedures for operating and monitoring the filter were also ineffective (ATSB, 2006). The above discussion clarifies that there is a need to address the proper maintenance planning onboard ships. The operation on-board ships at high seas are very complex in nature and is dependent on the competencies of the personnel operating and maintaining the machinery on-board. Also, the reliability of the system components must be high. This will ensure high reliability of the subsystems, which in turn will dictate high reliability of the main propulsion engine (Monieta, 2016). Assessment of main engine failures done by various groups have shown that the failures of pistons, piston rings, cylinder liners and geometry of the combustion chamber have highest proportion every year (Kamiski, 2017). Furthermore, research has been conducted to study the behaviour of the system components under various operational and maintenance policies. Therefore, it is required to evaluate an optimum maintenance plan which would ensure reliability of the main engine and at the same time economically viable (Baliwangi et al., 2009).

To make better maintenance plan it is required to assess the reliability of the marine engines. However, there is a lack of appropriate data and model that fits the data. Therefore, collecting the relevant appropriate data is very important. Currently there are limited data available in the literature however, it is not collected in a structured way to develop reliability assessment technique. To meet the scientific rigour and enable generalization of the data and its interpretation, various sources of data and modes of feedback, such as interviews with experienced seafarers' on-board, review of existing documentation, and a direct questionnaire method, can be used. It enables data collection from globally operating respondents. It widens the applicability of the method and helps to generalize the data and its interpretation. It is also an easy, effective, economical, flexible, and fast technique for data collection and development of a conceptual framework and has been previously used by researchers, Szolnoki and Hoffmann (2013), Attwood et al. (2006) Islam et al. (2018), Islam et al. (2017). Therefore, this approach is adopted in this study. The collected data is analysed through a series of statistical techniques to check the diversity and generalization of the data and its interpretation. Moreover, the collected relevant data from all the different sources used to identify the most appropriate failure model representing specific components of a marine engine. This model will be very useful to shipping companies for planning their maintenance of the main engine.

\section{QUESTIONNAIRE STRUCTURE}

The general structure of the questionnaire discussed in this section to better understand the responses. The main engine is associated with several subsystems to perform the task of propelling the huge merchant vessels (ABS, 2004). The key subsystems of a main engine are i) lubricating oil system ii) fuel oil system iii) cooling water system and iv) scavenge air system (Mollenhauer and Tschöke, 2010). The reliability of a marine engine is a product of the reliability of all the subsystems (i.e. lubricating oil system, fuel oil system, cooling water system and the scavenge air system). Therefore, the questionnaire structured in this study such a way that responses can be used to evaluate reliability of the each subsystem and finally to assess the reliability of a main engine (Mokashi et al., 2002). The questionnaire is given in the table 1 below.

Table 1. Questionnaire to seek the feedback from experience marine engineers

1 Please write the name of the engine and model number you have worked with (e.g. MAN B\&W 6SMC60) in the box below.

2 Please provide Failure Running Hours (FRH) for the following component in the tables below. For example, if the Planned Maintenance Hours (PMH) is 500 and the component fails 100 hrs before PMH, it means (FRH) for the component is 400. Please note FRH $<\mathrm{PMH}$.

\begin{tabular}{|l|c|c|c|c|c|c|}
\hline \multicolumn{7}{|c|}{ Lube oil system } \\
\hline & $\begin{array}{c}\text { Lube oil } \\
\text { suction filter }\end{array}$ & $\begin{array}{c}\text { Lube oil } \\
\text { pump }\end{array}$ & $\begin{array}{c}\text { Lube oil main } \\
\text { discharge filter }\end{array}$ & $\begin{array}{c}\text { Bypass lube } \\
\text { oil filter }\end{array}$ & Cooler & $\begin{array}{c}\text { Lube oil } \\
\text { temperature } \\
\text { controller }\end{array}$ \\
\hline FRH & & & & & & \\
\hline
\end{tabular}
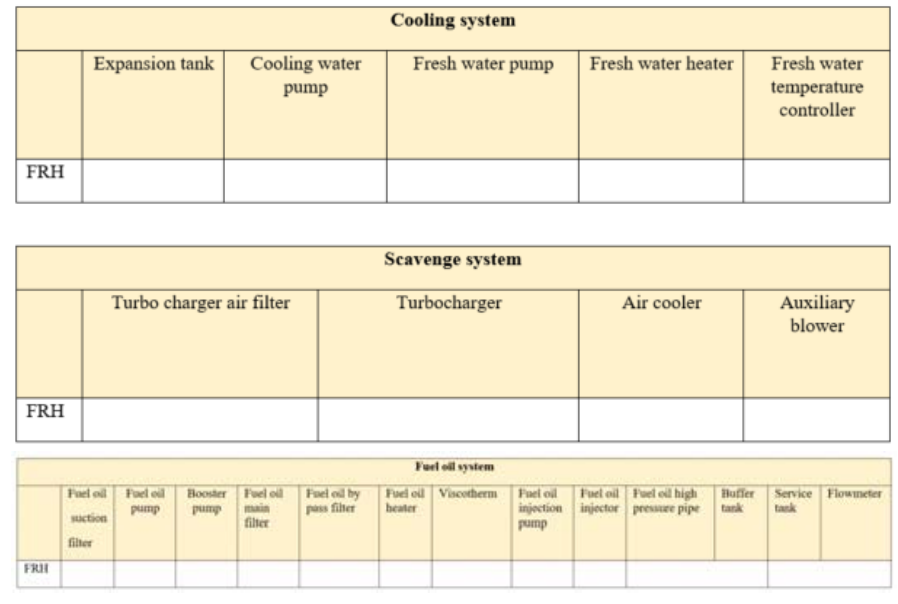

Question 1 seeks a response to identify the type of engine and its model (e.g. MAN B\&W 6SMC60).

Questions 2 seeks feedback to know the FRH for each individual components of a main engine subsystems. 


\section{SELECTION OF THE RESPONDENTS}

To complete the survey, a number of experienced marine engineers were identified in the shipping industry. The potential respondent selected based on the following criteria: i) at least 5-10 years of engine maintenance experience on-board ship, ii) has been sailing as $3^{\text {rd }}$ engineer, $2^{\text {nd }}$ engineer or chief engineer for ships engine department. A SurveyMonkey link was created to conduct the questionnaire survey. Ethics approval was sought, as per the guidelines of the University of Tasmania. Therefore, a human research ethics approval was obtained from the University of Tasmania's human research ethics committee (Ethics Ref No: H0014474). The SurveyMonkey link was sent around the world by email to a total of 200 experienced ship's engineers. The total responses received from the 101 respondents. In other words, the response rates are $50.5 \%$. Responses to these questions were analysed to qualify the subjectivity and uncertainty in the responses. To statistically validate the accuracy of the collected responses, the required sample size is estimated using Equation 1.

Required responses $\mathrm{n}=\frac{\mathrm{Z}^{2} \mathrm{P}(1-\mathrm{P})}{\mathrm{e}^{2}}$

(Islam and Yu, 2018, Islam et al., 2018, Islam et al., 2017)

where $\mathrm{e}$ is the margin of error $(\mathrm{e}= \pm 0.10)$; $\mathrm{Z}$ is normal scale value corresponding to $95 \%$ confidence. $\mathrm{P}$ is the level of satisfaction; it is considered to have the median value of 0.50 . Results of the required sample size demonstrate that it is necessary to have 96 responses from each department to statistically justify the accuracy of the collected response. The responses reported in this study are more than the required number of responses. This confirms the validity of enough responses and assumption of normality distribution of responses.

\section{STATISTICAL ANALYSIS OF THE DATA}

Statistical analysis is the science of collecting, examining, interpreting and presenting data to determine the basic form, relationships, and trends. Statistical analysis for research is necessary as it offers clarification of several concepts, theories, frameworks and methods. Moreover, it helps in arriving at conclusions and providing the hypothesis. Therefore, after collecting the data, the FRH was computed and statistical analysis was carried out. After collecting the data, a box plot of the data set was drawn in order to eliminate the outliers. A box plot is a method for individually and removed the outliers. The frequency plot for one of the sub-systems, viz. the cooling water system provided in Figure 1 below representing statistical data on a plot to visualize key statistical measures. The box plot drawn for all the components of a sub-systems.

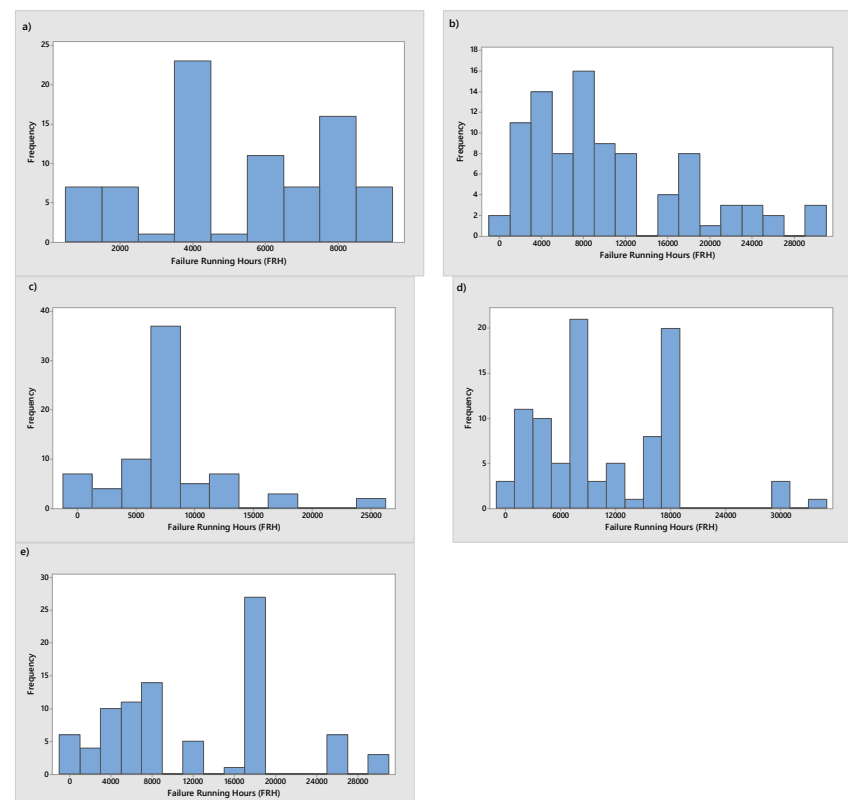

Figure 1. Frequency plot of Cooling Water System: a) Fresh Water Cooler, (b) Cooling Water Pump, (c) Expansion Tank, (d) Fresh Water Heater, (e) Fresh Water Temperature Control Valve.

The next part of the data analysis to produce a Box plot, Normal plot and the Weibull plot for the cooling water system components. The sample plots for two components; cooling water pump and the fresh water heater are shown in Figures 2 and 3 respectively.

\section{Cooling Water Pump}
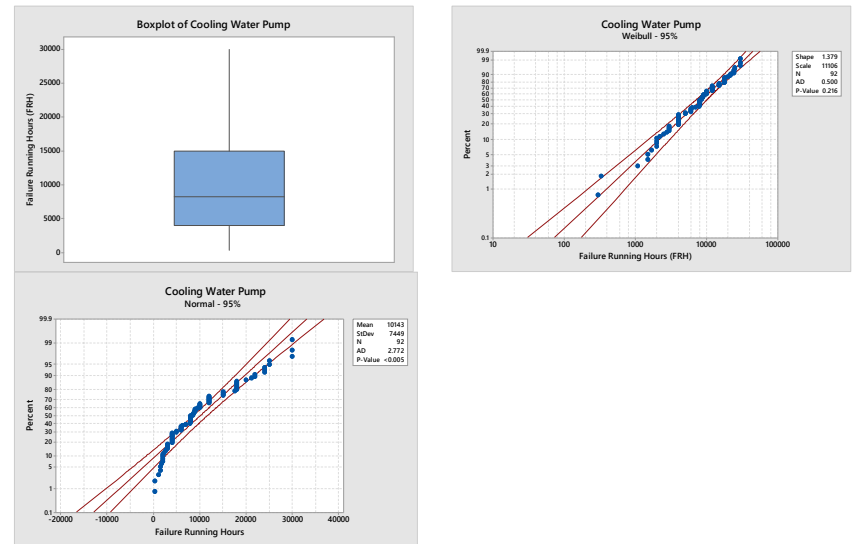

Figure 2. Box plot, Weibull plot and Normal plot for Cooling water pump
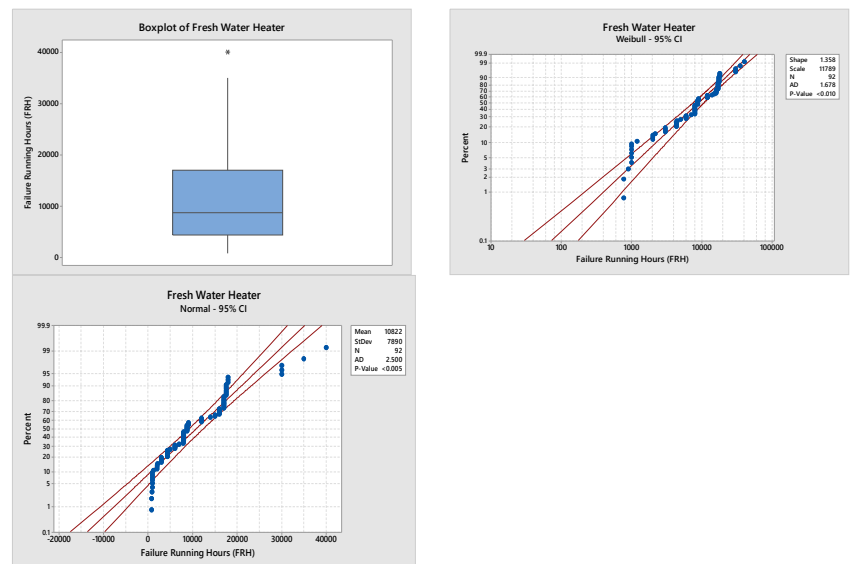

Figure 3. Box plot, Weibull plot and Normal plot for Fresh water heater 
Table 2. Tabulation of goodness of fit test for cooling water system

\begin{tabular}{lllllllllll}
\hline Cooling Water System & \multicolumn{3}{l}{ Distribution type } & \multicolumn{3}{l}{ B } & \multicolumn{3}{c}{ Best fit } \\
& \multicolumn{2}{l}{ Normal } & \multicolumn{2}{l}{ Exponential } & \multicolumn{2}{c}{ Weibull } & \multicolumn{3}{c}{ Gamma } & \multicolumn{2}{c}{ Distribution } \\
& P & AD & P & AD & P & AD & P & AD & \\
& value & value & value & value & value & value & value & value & \\
\hline Fresh Water Cooler & 0.005 & 8.725 & 0.003 & 5.690 & 0.010 & 3.493 & 0.005 & 2.895 & Gamma \\
Cooling Water Pump & 0.005 & 2.772 & 0.003 & 2.619 & 0.500 & 0.216 & 0.250 & 0.477 & Weibull \\
Expansion Tank & 0.005 & 8.122 & 0.003 & 6.903 & 0.010 & 4.789 & 0.005 & 4.683 & Gamma \\
Fresh Water Heater & 0.005 & 2.500 & 0.003 & 3.444 & 0.010 & 1.678 & 0.005 & 1.906 & Weibull \\
Fresh Water Temperature Control Valve & 0.005 & 2.437 & 0.003 & 3.714 & 0.010 & 1.680 & 0.005 & 1.841 & Weibull \\
\hline
\end{tabular}

$\mathrm{R}=\operatorname{Exp}(-\mathrm{t} / 11975.4)^{\wedge} 1.0705$

( Aplha 1.075, Beta is 11975.4)

$\mathrm{R}=\operatorname{Exp}(-\mathrm{t} / 14630.5)^{\wedge} 1.1264$

( Alpha 1.1264, Beta is 4630.5)
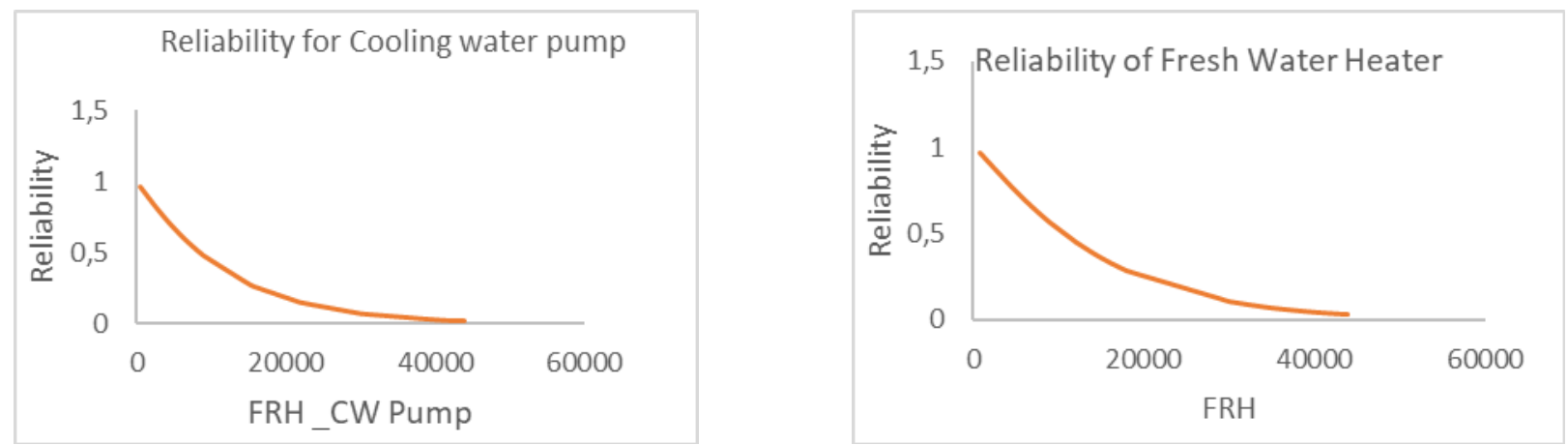

Figure 4. Weibull model for cooling water pump and fresh water heater

After drawing the probability plots for all the components of the cooling water system, the results were tabulated as shown in Table 2.

It is seen from the table above that $60 \%$ components of the cooling water system fitted the Weibull distribution and other $40 \%$ fitted Gamma distribution. Accordingly, it is suggested that the Weibull model could be a better fit for the cooling water system.

The data for the cooling water pump and fresh water heater was used to develop the Reliability model based on Weibull distribution The Alpha and Beta values were estimated and the Reliability equation for each of the component established. The Reliability for each of the component against the FRH is shown in Figures 4 below. A Chief Engineer on board the vessel can accordingly schedule his maintenance activities to achieve a high level of reliability.

\section{CONCLUSIONS}

This study provides useful data for the reliability analysis of a main propulsion engine. The collected data is unique in this field of study. The large set of collected data enables generalization and the processed data will help to develop reliability analysis techniques. The subjectivity and variability of the collected data are analysed, and it is found to be less than $10 \%$. Therefore, it provides a higher confidence in the data and its generalization. The analysis of the data collected through a structural survey demonstrates significance of the main propulsion engines' sub-systems and its components during the voyage. The collected relevant data from various sources are used to identify the most appropriate failure model representing specific components of a main propulsion engine. The results of this study indicate, not all the data for a component of a main propulsion engines' sub-system follow the same behaviour. Based on the observations and present data a Weibull model is suggested to estimate reliability of the cooling water system of the main engine.

\section{REFERENCES}

ATSB 2006. Independent investigation into the main engine failure on board the self discharging bulk carrier Enterprise.

ATTWOOD, D., KHAN, F. \& VEITCH, B. 2006. Offshore oil and gas occupational accidents-what is important? Journal of loss prevention in the process industries, 19, 386398.

BALIWANGI, L., ARTANA, K. B. \& ISHIDA, K. Risk based multi-objective simulation of ship main engine systems. 28th International Conference on Ocean, Offshore and Arctic Engineering, OMAE2009, May 31, 2009 - June 5, 2009, 2009 Honolulu, HI, United states. American Society of Mechanical Engineers (ASME), 181-188.

HATZIGRIGORIS, S., DRITSAS, C., HELIOTIS, A., SPERTOS, A., MORFINOS, C. \& KRIEZIS, G. Day-today challenges of a shipping company from the technical department's point of view - Lessons learned. 1st International Symposium on Ship Operations, Management and Economics 2005, 2005. Society of Naval Architects and Marine Engineers, 173-198.

INGLE, R. B., SAXENA, B. K. \& KHAN, M. A. J. 2010. A theoretical investigation of natural frequencies of vibration and noise due to engine and propeller systems of an Ultra Large Crude Carrier (ULCC). Journal of Low Frequency Noise, Vibration and Active Control, 29, 41-53.

ISLAM, R., ABBASSI, R., GARANIYA, V. \& KHAN, F. 2017. Development of a human reliability assessment technique for the maintenance procedures of marine and offshore operations. Journal of Loss Prevention in the Process Industries, 50, 416-428. 
ISLAM, R., KHAN, F., ABBASSI, R. \& GARANIYA, V. 2018. Human error assessment during maintenance operations of marine systems-What are the effective environmental factors? Safety science, 107, 85-98.

ISLAM, R., ABBASSI, R., GARANIYA, V. \& KHAN, F. 2017. Development of a human reliability assessment technique for the maintenance procedures of marine and offshore operations. Journal of Loss Prevention in the Process Industries, 50, 416-428.

ISLAM, R., KHAN, F., ABBASSI, R. \& GARANIYA, V. 2018. Human error assessment during maintenance operations of marine systems-What are the effective environmental factors? Safety science, 107, 85-98.

ISLAM, R. \& YU, H. 2018. Human Factors in Marine and Offshore Systems. In: FAISAL KHAN, R. A. (ed.) Methods in Chemical Process Safety. Elsevier.

KAMISKI, W. Assessment and analysis of selected main engines cylinder liners and piston rings wear process. 17th International Multidisciplinary Scientific Geoconference, SGEM 2017, June 29, 2017 - July 5, 2017,
2017 Albena, Bulgaria. International Multidisciplinary Scientific Geoconference, 97-104.

KIM, S.-E., CHOI, S.-H. \& VEIKONHEIMO, T. Model tests on propulsion systems for ultra large container vessel. The Twelfth International Offshore and Polar Engineering Conference, 2002. International Society of Offshore and Polar Engineers.

MONIETA, J. 2016. Ship fires caused by primary failure of the fuel filter of the engine driving the generator. Scientific Journals of The Maritime University of Szczecin, Zeszyty Naukowe Akademii Morskiej w Szczecinie, 119, 3641.

PITBLADO, R., BAIK, J. \& RAGHUNATHAN, V. 2006. LNG decision making approaches compared. Journal of hazardous materials, 130, 148-154.

PROPOSES, A. C. Bulk Shipping Concept Aims to Expand Capacity of Shallow-water Ports.

SZOLNOKI, G. \& HOFFMANN, D. 2013. Online, face-toface and telephone surveys-Comparing different sampling methods in wine consumer research. Wine Economics and Policy, 2, 57-66. 